\title{
Diagnostic efficacy of chlamydial antibodies in cervical secretions from pregnant women and adolescent girls
}

\author{
Henning Thejls, Vivi-Anne Rahm, Judy Gnarpe, Håkan Gnarpe
}

\begin{abstract}
Objective-To assess the prevalence of cervical antibodies to Chlamydia trachomatis in two different populations and to correlate the findings to culture, direct fluorescent antibody test (DFA) and serum antibodies.
\end{abstract}

Setting-Antenatal clinics and clinic for teenage counselling in Gävle.

Patients-1078 pregnant women attending for routine follow up in the third trimester of pregnancy and 256 teenage girls.

Outcome measures-Cervical IgG and IgA antibodies to Chlamydia trachomatis. Cervical cultures for chlamydia. Serum IgG antibodies. DFA tests were used only in the teenage group.

Results-The prevalence of positive culture was $2 \cdot 0 \%$ in pregnant women and $8.6 \%$ in teenage girls. In pregnant women cervical IgG $\geqslant 8$ and IgA $\geqslant 8$ were found in $7 \cdot 2 \%$ and $5 \cdot 8 \%$ respectively and in teenage girls in $6.6 \%$ and $2 \cdot 0 \%$ respectively. The agreement between cervical IgG $\geqslant 8$ and humoral IgG $\geqslant 32$ was 0.76 in the pregnant group and 0.95 in the teenage group. The sensitivity, specificity and positive predictive value (PPV) for cervix IgG $\geqslant 8$ to predict a positive culture was $0.64,0.94$ and 0.18 respectively in pregnant women and $0.41,0.97,0.53$ respectively in teenage girls. Of 31 teenage girls with either positive culture or positive DFA 12 had cervical IgG $\geqslant 8$ while five of 225 with negative chlamydia tests had cervical IgG $\geqslant 8$ (sensitivity 0.40 and PPV of 0.71). Cervical IgG $\geqslant 16$ was found in eight of 31 with positive chlamydia tests and in one of 225 with negative tests (sensitivity 0.26 and PPV 0.89).

Conclusions-The finding of cervical IgG $\geqslant 16$ predicts current chlamydia (culture or DFA) in nearly $90 \%$ in a teenage population. It might indicate current infection in spite of negative culture in some cases. For low titres and in a low prevalence pregnant population cervical IgG are not useful for the diagnosis of chlamydia. As the sensitivity is low cervical antibodies cannot be used for screening purposes.

(Genitourin Med 1995;71:370-374)

Key words: chlamydia trachomatis; antibodies; cervix
Introduction

The diagnostic significance of the finding of cervical antibodies to Chlamydia trachomatis has been a matter of debate. There have been three main questions to consider: (1) Does the finding of local antibodies correlate so well with culture that it may be used as a screening method? (2) Does the finding of local antibodies express current infection in spite of negative culture? (3) Are local antibodies produced locally or do they reflect the level of serum antibodies?

Several authors have stated that the local production of antibodies is short lived and temporally associated with current infection and therefore correlates better with current infection than humoral antibodies. ${ }^{1-3}$ The cellular immune response, as measured by the lymphocyte proliferation response, has been shown to be higher when cervical antibodies are present than when they are absent. ${ }^{4}$ Cervical antibodies might therefore be of help as diagnostic support.

Studies on the correlation of cervical antibodies and chlamydial culture have given divergent results. The sensitivity and positive predictive value (PPV) have ranged from $0.64-1.00$ and $0.26-0.78$ respectively. ${ }^{15-8}$

The most useful attribute of a diagnostic test for the clinician is a high PPV as pointed out by Schacter et al ${ }^{8}$ who found a sensitivity of 1.00 but PPV of only 0.26 for cervical IgG in a high prevalence population $(20 \%$ positive culture). None of the studies mentioned above has found that local antibodies safely predict a positive outcome of culture of a single cervical specimen. But it has been suggested that positive antibody tests with negative culture might signify either current infection not possible to culture or recent infection.'

In animal models high estradiol levels have been shown to inhibit the secretion of genital IgG. ${ }^{9}$ The high levels of steroids during pregnancy might have a similar effect on the secretion of cervical antibodies in pregnant women. A comparison of pregnant and nonpregnant women could therefore be of interest.

The aims of this study were to analyse the findings of cervical antibodies in pregnant women and adolescent girls with respect to difference in prevalence between the populations, correlation between cervical antibodies and chlamydia infection as diagnosed by culture and/or direct fluorescent antibody test (DFA) and the correlation of serum antibodies to cervical antibodies. 
Materials and methods

THE STUDY POPULATION INVOLVED TWO DIFFERENT GROUPS

Group One: One thousand seventy eight consecutive pregnant women in the third trimester who presented at the antenatal clinics in Gävle during one year. The patients came for routine check ups. The mean age was 27.9 (range 17-53) years. Specimen collection included cervical culture for Chlamydia trachomatis, cervical IgG and IgA and serum IgG antibodies to Chlamydia trachomatis.

Group Two: Two hundred and fifty six sexually active female patients attending an adolescent clinic during a period of three months. The mean age was 17.5 years (range 14-21). All patients whose visit included a gynaecological examination were enrolled in the study. The reasons for attending were family planning in $149(58.2 \%)$ cases, suspected genital infection due to discharge in 58 $(22.7 \%)$, male partner with symptoms in 14 $(5.5 \%)$ and other gynaecological problems in $35(1 \cdot 7 \%)$ cases. Specimen collection included cervical culture and DFA test, cervical IgG and IgA antibodies and serum IgG antibodies.

\section{SPECIMEN COLLECTION}

Blood was collected from group one by venipuncture and from group two by capillary sampling. The capillary samples and specimens from cervical secretions were collected with a cellulose sponge of about $10 \times 5 \times 1 \mathrm{~mm}$, precalibrated to contain $100 \mu \mathrm{l}$ fluid (John Weis and Son Ltd, London), kindly provided by Professor S. Darougar, London. The sponge was held with a forceps in the cervical channel and allowed to be saturated with secretion. It was then placed in an empty plastic tube for transport to the laboratory. The cervix was then cleansed with a swab and a specimen for chlamydia culture was collected with an alginate tipped aluminium wire swab (CTA swab) and placed in 2SP transport medium. The three specimens were sent to the laboratory the same day. When possible, specimens were cultured on the day of arrival. Specimens arriving late were held at $4^{\circ} \mathrm{C}$ and cultured the next day. Specimens taken on Fridays were placed at $-70^{\circ} \mathrm{C}$ for culture the following Monday. In group two the swab used for culture was first rolled on a glass microscope slide for the DFA test, air dried and fixed with ethanol. The slide was then stained with fluorescein isothiocyanide conjugated monoclonal antibodies.

\section{LABORATORY PROCEDURES}

The specimens in 2SP medium were inoculated on monolayers of cycloheximide treated McCoy cells in 24-wells plates and centrifuged at $1800 \mathrm{~g}$ for one hour at $35^{\circ} \mathrm{C}$. Staining was done with fluorescein isothiocyanate conjugated monoclonal antibodies (SYVA Culture Confirmation, SYVA, San José, CA) after 48 hours of incubation in $5 \% \mathrm{CO}_{2}$. The blood samples were analysed using an indirect microimmunofluorescence test (MIF) based on egg cultured elementary bodies from Chlamydia trachomatis, serovars D-K. ${ }^{10}$ The sponges containing blood or cervical fluids were frozen on arrival to the laboratory at $-70^{\circ} \mathrm{C}$ until processed. $700 \mu \mathrm{l}$ of phosphate buffered saline, $\mathrm{pH} 7 \cdot 2$ was added to each specimen to elute the fluid, providing a titre of $1: 8$. Each specimen was then tested for $\mathrm{IgG}$ and IgM antibodies by MIF. Specimen dilutions were incubated on the slides for $30 \mathrm{~min}$ utes at $37^{\circ} \mathrm{C}$, after which a washing procedure of 3 times 5 minutes was initiated. Slides were then air-dried, and fluorescein isothiocyanate conjugated antihuman IgG or IgA was applied. Incubation was carried out at $37^{\circ} \mathrm{C}$ for 30 minutes, after which another washing procedure was carried out. After air-drying, the slides were mounted using glycerol and examined in a Zeiss UV microscope, at a magnification of $400 \times$. All specimens positive in 1:8 titres were titrated further until the endpoints were reached. The DFA preparations were stained using the monoclonal, MicroTrak Chlamydia trachomatis Direct Specimen Test (SYVA Company, San José, CA). The total number of EBs per slide were counted and given as result. The manufacturer recommends that only slides with $\geqslant 10 \mathrm{EBs}$ are regarded as positive while slides with lower counts are suspected positive.

\section{STATISTICAL METHODS}

To compare the titres of cervical antibodies and the finding of current chlamydia (culture and/or DFA test) in $2 \times 2$ tables, the titre levels were divided into two categories using a cutoff of 8 and a cut-off of 16 . The sensitivity is calculated as the proportion of true positive tests to all positive cases, the specificity as the proportion of true negative tests to all negative cases, PPV as the proportion of true positive tests to all positive tests and the negative predictive value (NPV) as true negative tests to all negative tests. The agreement is the proportion of all true tests results (positive + negative) to all tests. The likelihood ratio (LR) is calculated as sensitivity/(1-specificity), that is, the proportion of the probability of having the disease when the test is positive and the probability of not having the disease when the test is positive. As it is independent of the prevalence, the LR from populations with different prevalence of disease can be compared directly. ${ }^{11}$ As a rough guide LR values of $1-2$ indicate no or minimal effect on diagnosis, 2-5 indicate small but sometimes important impacts on diagnosis, 5-10 gives moderate impact and values $>10$ gives large and mostly conclusive changes from pre-test to post-test probability of disease ${ }^{11}$. The LR is given with $95 \%$ confidence interval. ${ }^{12}$

The two sided chi square test with Yates' correction was performed for all $2 \times 2$ tables. The Spearman rank order correlation was calculated to evaluate the progressive correlation between the titre values of serum IgG and cervical IgG.

\section{Results}

PREVALENCE OF ANTIBODIES

The teenage group had the lowest prevalence 
Table 1 Prevalence of culture and antibody levels in 1078 pregnant women and 256 adolescent girls

\begin{tabular}{lcll}
\hline Measurement & $\begin{array}{l}\text { Pregnant women } \\
n(\%)\end{array}$ & $\begin{array}{l}\text { Adolescent girls } \\
n(\%)\end{array}$ & p-value \\
\hline Culture & $22(2 \cdot 0)$ & $22(8 \cdot 6)$ & $<0 \cdot 001$ \\
Serum IgG $\geqslant 32$ & $308(28 \cdot 6)$ & $19(7 \cdot 4)$ & $<0 \cdot 001$ \\
Serum IgG $\geqslant 64$ & $143(13 \cdot 3)$ & $13(5 \cdot 0)$ & $<0 \cdot 001$ \\
Cervical IgG $\geqslant 8$ & $78(7 \cdot 2)$ & $17(6 \cdot 6)$ & NS \\
Cervical IgG $\geqslant 16$ & $27(2 \cdot 5)$ & $9(3 \cdot 5)$ & NS \\
Cervical IgA $\geqslant 8$ & $63(5 \cdot 8)$ & $5(2 \cdot 0)$ & $<0 \cdot 025$ \\
Cervical IgA $\geqslant 16$ & $12(1 \cdot 1)$ & $2(0 \cdot 8)$ & NS \\
\hline
\end{tabular}

of serum IgG of the two groups in spite of the highest prevalence of positive chlamydia culture (table 1). The differences are highly significant. Cervical IgA was found in only five $(2 \%)$ cases in the teenage group compared with $63(6 \%)$ in the pregnant group ( $p<$ $0 \cdot 025)$. The prevalence of cervical IgG did not differ for the two groups (table 1 ).

\section{CORRELATION OF CERVICAL ANTIBODIES TO CURRENT INFECTION}

The diagnostic efficacy for cervical IgG with a cut-off at a titre of 8 and 16 respectively is illustrated in table 2 .

Of 22 pregnant women with positive culture 14 had cervical IgG $\geqslant 8$ while of 1056 pregnant women with negative culture 64 had cervical $\mathrm{IgG} \geqslant 8$. The sensitivity for this cut-off is 0.64 and the PPV is 0.18 to be compared with the prevalence of 0.02 (table 2). Of 22 pregnant women with positive culture $10 \mathrm{had}$ IgG $\geqslant 16$ while of 1056 with negative culture 17 had IgG $\geqslant 16$. Using this cut-off the PPV is augmented from 18 to 37 while the sensitivity is reduced to $0 \cdot 45$. The likelihood ratios for the two cut-offs are 10.5 and 28 respectively.

Even for the teenage group the PPV of cervical IgG is clearly augmented when higher cut-offs are used but on a higher level as the prevalence is higher for the teenage group $(8.6 \%)$. Of 22 teenagers with positive culture, nine had IgG $\geqslant 8$ while of 234 with negative culture 8 had cervical IgG $\geqslant 8$. The sensitivity for this cut-off is 0.41 and the PPV is 0.53 .

Of 22 teenagers with positive culture 6 had IgG $\geqslant 16$ while of 234 with negative culture only three had cervical IgG $\geqslant 16$. The PPV for this comparison is 0.67 while the sensitivity is reduced to $0 \cdot 27$. The likelihood ratios (LR) in the two populations do not differ significantly for the same titre level of cervical IgG but the $95 \%$ confidence interval is broader for the teenage group as there were fewer cases.

In the pregnant group cervical $\operatorname{IgA} \geqslant 8$ was found in 13 of 22 with positive culture while 50 of 1056 with negative culture had IgA $\geqslant 8$. This gives sensitivity, specificity, PPV, NPV and a total agreement of $0.59,0.95,0.21,0.99$ and 0.95 respectively (table 2 ). Cervical IgA $\geqslant 16$ was found in only 12 patients of which seven were positive in culture. The resulting sensitivity and specificity for IgA $\geqslant 16$ is 0.32 and 0.995 respectively and the LR 67 (23-196) which express a very strong correlation with positive culture. This gives a positive predictive value of 0.58 which in this context is a high value for a population with a prevalence of only $2 \%$ but still not sufficient to make it useful as a diagnostic test.

The highest serum IgG titre in the pregnant group was 256. Eleven cases had a titre of 256 and all had negative cultures. A titre of 128 was found in 21 cases of which only two had a positive culture. Eight of a total of 22 cases with positive culture had serum IgG titre $<32$.

In the teenage group more than $10 \mathrm{EBs}$ were found in 20 of 22 cases with positive cultures and in nine of 234 with negative cultures. It follows that current chlamydial infection defined as positive culture and/or more than 10 EBs in the DFA test was found in $31(12 \%)$ of 256 patients. Twelve of these 31 patients had cervical IgG $\geqslant 8$ while five of 225 patients without infection had IgG $\geqslant 8$. The resulting PPV is thereby augmented to 0.71 compared with 0.53 when cervical $\operatorname{IgG} \geqslant 8$ is related to culture alone (table 3 ). The corresponding sensitivity and specificity is 0.39 and 0.98 respectively. If this same criterion for current chlamydial infection is compared with cervical IgG $\geqslant 16$ we found that eight of nine cases with $\geqslant 16$ in cervical IgG had current infection while only one of 225 without infection had cervical IgG $\geqslant 16$. The PPV and specificity for this comparison is 0.89 and 0.995 respectively but the sensitivity is only $0 \cdot 26$.

Of nine teenage girls with negative culture but positive DFA test, three had cervical IgG while of 225 with negative DFA test as well

Table 2 Diagnostic efficacy of cervical antibodies to predict positive cervical culture in pregnant women and adolescent girls. Prevalence independent and prevalence dependent statistics

\begin{tabular}{|c|c|c|c|c|c|}
\hline \multirow[b]{2}{*}{ Statistic } & \multicolumn{3}{|c|}{$\begin{array}{l}\text { Pregnant women } \\
N: 1078\end{array}$} & \multicolumn{2}{|c|}{$\begin{array}{l}\text { Adolescent girls } \\
N: 256\end{array}$} \\
\hline & $\operatorname{Ig} A \geqslant 8^{\star}$ & $I g G \geqslant 8 \dagger$ & $I g G \geqslant 16 \ddagger$ & $I g G \geqslant 85$ & $\operatorname{Ig} G \geqslant 16 \|$ \\
\hline $\begin{array}{l}\text { Sensitivity } \star \star \\
\text { Specificity }{ }^{\star \star} \\
\text { Agreement } \\
\text { Likelihood Ratio }{ }^{\star \star} \\
95 \% \text { confidence interval } \\
\text { Positive Predictive Valuett } \\
\text { Negative predictive valuett } \\
P \text {-value for the } 2 \times 2 \text { table }\end{array}$ & $\begin{array}{c}0.59 \\
0.95 \\
0.95 \\
12 \\
8-19 \\
0.21 \\
0.99 \\
<0.001\end{array}$ & $\begin{array}{c}0.64 \\
0.94 \\
0.93 \\
11 \\
7-16 \\
0.18 \\
0.99 \\
<0.001\end{array}$ & $\begin{array}{c}0.46 \\
0.98 \\
0.97 \\
28 \\
15-55 \\
0.37 \\
0.99 \\
<0.001\end{array}$ & $\begin{array}{l}0.41 \\
0.97 \\
0.92 \\
12 \\
5-28 \\
0.53 \\
0.95 \\
<0.001\end{array}$ & $\begin{array}{l}0.27 \\
0.99 \\
0.93 \\
21 \\
6-79 \\
0.67 \\
0.94 \\
<0.001\end{array}$ \\
\hline
\end{tabular}

$\star 13$ culture positive of 63 with cervix IgA $\geqslant 8$ and a total 22 of 1078 with positive cultures.

+14 culture positive of 78 with IgG $\geqslant 8$.

$\ddagger 10$ culture positive of 27 with IgG $\geqslant 16$.

$\$ 9$ culture positive of 17 with IgG $\geqslant 8$ of total 22 of 256 with positive cultures.

$\| 6$ culture positive of 9 with $\operatorname{IgG} \geqslant 16$.

$\star \star$ Prevalence independent.

t†Prevalence dependent. 
Table 3 Diagnostic efficacy for cervical IgG in teenage girls when current chlamydia infection is defined as positive culture or $\geqslant 10 \mathrm{EBs}$ in the DFA test

\begin{tabular}{lll}
\hline & \multicolumn{2}{l}{ Culture positive or DFA $\geqslant 10$ EBs. N: 31} \\
\cline { 2 - 3 } Statistic & $I g G \geqslant 8^{\star}$ & $\operatorname{IgG} \geqslant 16 \dagger$ \\
\hline Sensitivity & 0.39 & 0.26 \\
Specificity & 0.98 & 0.995 \\
Likelihood ratio & 17 & 58 \\
$95 \%$ confidence interval & $7-46$ & $8-449$ \\
PPV & 0.71 & 0.89 \\
NPV & 0.92 & 0.91 \\
$p$-value for 2 $\times 2$ table & $<0.001$ & $<0.001$ \\
\hline
\end{tabular}

$\star 12$ of 31 with current chlamydia and 5 of 225 without infection.

t8 of 31 with current chlamydia and 1 of 225 without infection.

as negative culture five had cervical IgG $(\mathrm{p}<0.001)$.

In the teenage group only five cases with cervical IgA were found. Two of these had positive chlamydial cultures, one had $15 \mathrm{EBs}$ in the DFA test but negative culture and two were negative in both culture and DFA. None of these had positive serum IgA. Positive serum IgA was found in only three teenage girls of whom two had positive culture and $\geqslant 100 \mathrm{EBs}$ in the DFA test.

\section{CORRELATION OF CERVICAL ANTIBODIES TO HUMORAL ANTIBODIES}

When the IgG results are divided into groups with titre of $\geqslant 8$ or $<8$ for cervical IgG and $\geqslant 32$ or $<32$ for humoral IgG it was found that $62(79 \%)$ of 78 pregnant women with cervical IgG $\geqslant 8$ had serum IgG $\geqslant 32$ giving a total agreement of $76 \%$ (62 cases positive in both tests and 754 negative in both tests of a total of 1078). The linear correlation of the cervical and humoral titre values was relatively poor as expressed by the Spearmans rank order correlation $(r=0 \cdot 30)$. For the teenage group 11 cases of 17 with cervical $\mathrm{IgG} \geqslant 8$ had serum IgG $\geqslant 32$ while 231 cases with cervical IgG $<8$ had serum IgG $<32$ giving an agreement of $95 \%$. The Spearmans rank correlation was 0.58 . The distribution of culture, DFA and antibody findings between the four anamnestic subgroups of adolescent girls showed no statistically significant differences.

\section{Discussion}

Very few studies have evaluated the prevalence of cervical antibodies in pregnant women and teenage girls. Grönros et $a l^{13}$ found cervical IgA in $41.3 \%$ pregnant women applying for abortion compared with $5.8 \%$ in our study in spite of the same prevalence of positive cultures $(2 \cdot 7 \%)$. To our knowledge no studies of cervical antibodies in a teenage population have been published before.

The two groups in our study differed in prevalence of positive culture as expected. In spite of that, the finding of serum IgG and cervical IgA were more common in the low prevalence pregnant group. These findings may express a history of prior chlamydia infection, that should be more common in an older patient group than in a younger, and perhaps infections with longer duration giving a more pronounced antibody response.

Cervical IgG is considered to be a mixture of transudated antibodies from the circulation and antibodies produced by plasma cells in the basal layers of the mucosal membrane. ${ }^{14}$ They seem to be a part of a general mucosal immune response as oral immunisation can induce immunity in other parts of the body. ${ }^{14}$

Our study shows an agreement of $95 \%$ between cervical IgG and serum IgG for the teenage group but only $76 \%$ in the pregnant group and a poor linear correlation. The proportion of cervical IgG to humoral IgG is lower in the pregnant group. These findings might express an inhibitory effect of steroids on the local IgG secretion as indicated by animal experiments ${ }^{9}$ or that local production is independent of the humoral IgG titres.

The poor correlation of serum IgG and culture is illustrated by the lack of serum IgG in 8 (36\%) of 22 cases with positive cultures in the pregnant group.

The results obtained by comparing cervical IgG $\geqslant 8$ or IgA $\geqslant 8$ (pregnant group) with positive tissue culture from cervical specimens fall within the broad range of results obtained in the studies mentioned in the introduction. ${ }^{15-8}$ In the study of Treharne $e t a l^{7}$ the authors focused on the sensitivity of the method. For cervical IgG titres of $\geqslant 8$ they found a sensitivity of 0.74 compared with 0.64 in our study and a PPV of 0.39 (26/66) for cervical IgG (our calculation) and in our study 0.18 for the pregnant group but 0.53 for the teenage group.

The specificity and PPV increase substantially when the cut-off titre of 16 is chosen for the local IgG. This is even more pronounced for cervical IgA in the pregnant group.

A notable finding is the correlation of positive DFA and local antibodies in the adolescent group. If DFA tests with more than 10 EBs despite negative cultures are included the PPV and LR seems to increase very substantially. The relatively few cases calls for some caution in the interpretation but even when the broad confidence interval is taken into account the increase seems to be real. If all positive cultures are excluded from the comparison and only DFA tests with $\geqslant 10$ EBs and negative culture are compared with the finding of local antibodies a strong correlation of cervical antibodies and DFA results is still found. This adds to the speculation that local antibodies can express current infection in spite of negative culture and DFA might detect some of these.

Other authors have suggested that cases positive for local antibodies but negative in culture might represent patients with active chlamydia unable to grow in culture. ${ }^{1}$ Disappearance of cervical antibodies parallel to cytological signs of chlamydial infection after treatment have been demonstrated in a few cases. ${ }^{15}$ In studies of chronic prostatitis IgA antibodies against Chlamydia trachomatis has been suggested as expressing current infection in spite of negative culture. An intervention study by Bjercke and Purvis ${ }^{16}$ has shown the disappearance of seminal antibodies after treatment with antibiotics and even disappearance of serum IgA in the treated female 
partner. Chlamydia trachomatis has recently been demonstrated by PCR in seminal fluid ${ }^{17}$ in spite of negative culture. It seems therefore to be indirect evidence for the idea that local IgA might be a marker of current infection.

In conclusion we found that serum IgG to Chlamydia trachomatis is more common and the proportion between cervical and humoral IgG lower in pregnant women than in teenage girls. Epidemiological differences and mucosal changes during pregnancy may partly explain the difference. Cervical antibody titres correlate in a progressive way to the finding of chlamydia either by culture or DFA. The sensitivity is low and the specificity insufficient to make measurement of cervical antibodies useful as a screening method, but it may be helpful in the clinical evaluation of high prevalence populations. The finding of cervical antibodies in titres $\geqslant 16$ should encourage the clinicians not to accept a negative culture as a true negative before thorough follow ups with multiple tests have been performed. To what extent local antibodies express current infection in spite of negative culture needs further evaluation with multiple non-culture tests.

1 McComb DE, Nichols RL, Semine DZ, et al. Chlamydia trachomatis in Women: Antibody in cervical secretions as a possible indicator of genital infection. F Infect Dis 1974 139:628-33.

2 Allardyce RA, Bienenstock J. The mucosal immune system in health and disease, with an emphasis on parasitic infection. Bull WHO 1984;62:7-25.

3 Jones RB, Batteiger BE. Human immune response to Chlamydia trachomatis infections. In: Oriel JD, Ridgway
JO, Schachter G, Taylor-Robinson D, Ward M. eds. Chlamydial Infections. Cambridge: Cambridge University Press, 1986:423-32.

4 Brunham RC, Martin DH, Kuo C-C, et al., Cellular immune response during uncomplicated genital infection with Chlamydia trachomatis in humans. Infect Immun 1981;34:98-104.

5 Richmond SJ, Milne JD, Hilton AL, Caul EO. Antibodies to Chlamydia trachomatis in cervicovaginal secretions: relation to serum antibodies and current chlamydial infection. Sex Transm Dis 1980;7:11-15.

6 Southgate LJ, Treharne JD, Forsey T. Chlamydia trachomatis and Neisseria gonorrhoeae infections in women attending inner city general practices. Sex Transm Dis ing inner city $1983 ; 287: 879-81$.

7 Treharne JD, Darougar S, Simmons PD, Thin RN. Rapid diagnosis of chlamydial infection of the cervix. $\mathrm{Br} \mathcal{F}$ Venereal Dis 1978;54:403-8.

8 Schachter J, Cles L, Ray R, Hines PA. Failure of serology in diagnosing chlamydial infections of the female genital tract. $\mathcal{F}$ Clin Microbiol 1979;10:647-9.

9 Rank RG, Barron AL. Specific effect of estradiol on the genital mucosal antibody response in chlamydial ocular and genital infections. Infect Immun 1987;55:2317-9.

10 Treharne JD, Darougar S, Jones BR. Modification of the micro-immunofluoresence test to provide a routine serodiagnistic test for chlamydial infections. $f$ Clin Pathol 1977;30:510-7.

11 Jaeschke R, Guyatt GH, Sackett DL. Users' guides to the medical literature. III. How to use an article about a medical literature. III. How to use an article about a diagnostic test. $\mathrm{B}$. What are the results and will they help
me in caring for my patients? $¥ A M A \quad 1994 ; 271: 703-7$.

12 Morris JA, Gardner MJ. Calculating confidence intervals for relative risks, odds ratios, and standardised ratios and rates. In: Gardner MJ, Altman DG, eds. Statistics with Confidence. Confidence intervals and statistical guidelines. London: $B M \mathcal{F}$ 1989:50-2.

13 Grönros M, Honkonen E, Terho P, Punonen R. Cervical and serum IgA and serum IgG antibodies to Chlamydia trachomatis and herpes simplex virus in threatened abortion: a prospective study. $\mathrm{Br} ₹$ Obstet Gynaecol 1983;90: 167.

14 Briese VV. Humorale aspekte der schleimhautimmunitätPerspektiven für den weiblichen genitaltrakt. Zentbl Perspektiven für den we

15 Carr MC, Hanna L, Jawetz E. Chlamydiae, Cervicitis, and abnormal papanicollaou smears. Obstet Gynecol 1979;53: $27-30$

16 Bjercke S, Purvis K. Chlamydial serologi in the investigation of infertility. Hum Reprod 1992;7:621-4.

17 Witkin SS, Jeremias J, Grifo JA, Ledger WJ. Detection of Chlamydia trachomatis in semen by the polymerase chain reaction in male members of infertile couples. Am $\mathcal{F}$ Obstet Gynecol 1993;168:1457-62. 